\title{
ELEMENTOS ARQUEOSEMIÓTICOS Y PINTURAS RUPESTRES EN EL DESIERTO DE ATACAMA (NORTE DE CHILE)
}

\author{
ARCHAEOSEMIOTICS AND ROCK ART PAINTINGS IN THE ATACAMA DESERT \\ (NORTHERN CHILE)
}

\author{
Pedro Mege R. ${ }^{1}$ y Francisco Gallardo I. ${ }^{1}$
}

\begin{abstract}
El fracaso de los enfoques semiológicos aplicados al arte rupestre tiene su origen en el intento de atribuirle un carácter fonémico, es decir, la reducción de la expresión visual a su contenido o expresión verbal. En tanto que la mayoría de los casos rupestres el significado es inaccesible, es claro que el punto de partida debe necesariamente descansar en el significante. En el presente artículo exploramos en una nueva vía de análisis, que apela a un lenguaje intersemiótico que se nutre tanto de la semiótica como de la arqueología. Fundados en este diálogo o arqueosemiótica, consideramos aquí los estilos de arte rupestre como un sistema, como una configuración de significantes distintivos organizados en relaciones, vínculos que constituyen una estructura visual culturalmente significativa. Estas soluciones definen la arquitectura de modos de ver determinados histórica y socialmente, arreglos que distinguen a dos estilos de pintura rupestre de la región atacameña que nos sirven de casos de estudio: los estilos Confluencia (Formativo Temprano 4.000-2.400 a.p.) y Cueva Blanca (Formativo Tardío 2.400-1.600 a.p.).
\end{abstract}

Palabras claves: arqueosemiótica, estilo, arte rupestre, modos de ver, período Formativo, desierto de Atacama.

Semiological perspectives applied to rock art have been unsuccessful. This failure results from attributing a phonemic nature to it, that is to say, from reducing its visual expression to its content. While in most rock art what is signified is no longer accessible, it is evident that the starting point should necessarily be the signifier. In this paper, we explore a new perspective using an intersemiotic language based on the relationship between semiotics and archaeology. In this dialogue, art styles are understood as a configuration of distinctive signifiers, bonds that establish a culturally meaningful visual structure. These solutions define the architecture of socially and historically determined ways of seeing and distinguish the two rock art cases in the Atacama region which are the focus of our study: Confluencia Style (Early Formative Period 4,000-2,400 BP) and Cueva Blanca Style (Late Formative Period 2,400-1,600 BP).

Key words: Archaeosemiotics, style, rock art, ways of seeing, Formative Period, Atacama desert.

La finalidad de este trabajo es presentar una selección de conceptos pertenecientes a la semiología y la arqueología, que permitan un primer arreglo arqueosemiótico para ese dominio conocido como arte rupestre. Se trata de un esfuerzo metodológico que busca la pertinencia de una estrategia distinta a la propuesta por modelos semiológicos de corte lingüístico clásico, saussureanos y martineteanos. Perspectivas que hasta ahora han demostrado evidentes limitaciones metodológicas en el campo de la interpretación del arte rupestre (p.ej., Kechagia 1995; Llamazares 1986).

El obstáculo metodológico enfrentado al abordar la especificidad del significante rupestre, se origina en su intento de atribuirle un carácter fonémico, es decir, la reducción de esta expresión visual por el contenido o expresión verbal. Siguiendo a
Kenneth Pike (1943), el esfuerzo arqueosemiótico debería orientarse en un sentido fonético, ir a lo material de la expresión, siguiendo la analogía lingüística, su sonido y no al sonido dentro de una específica asignación cultural, en definitiva, de su significado. Tomar este último camino hace imposible la discriminación de una unidad mínima de significación fonémica -distinguir morfemas en el plano figurativo- y menos aún fundar una sintagmática. Por consiguiente, la pretensión de establecer unidades mínimas de significación en una doble articulación, es simplemente un callejón sin salida. Sin duda, los esfuerzos de dar con un "lenguaje visual" han llevado al fracaso a los enfoques semiológicos en el campo del arte rupestre. La clave pareciera estar, como dice Sorensson (1994), en dilucidar la naturaleza del signo pictórico por medio

\footnotetext{
1 Centro Interdisciplinario de Estudios Interculturales e Indígenas, Pontificia Universidad Católica de Chile, Campus San Joaquín,
} Avda. Vicuña Mackenna 4860, Macul, Santiago, Chile.pmeger@uc.cl; fgallardo.ibanez@gmail.com 
de un lenguaje intersemiótico de traducción entre la semiótica y la arqueología. En lo general, nuestro esfuerzo se orienta en el sentido que Sorensson da al análisis del arte rupestre, pues para descubrir la naturaleza semiótica de estos hechos, es necesario dar con la clave de construcción del signo visual y diferenciar sus "rasgos distintivos" o paradigmas de representación".

En el presente artículo exploraremos en una arqueosemiótica del arte rupestre, considerando el estilo como una configuración de significantes distintivos organizados en relaciones, vínculos que constituyen una estructura visual culturalmente significativa (Gombrich 2002; Kubler 1987:173). Estas soluciones definen la arquitectura de modos de ver determinados histórica y socialmente (Berger 1975), arreglo que es el que distingue a dos estilos de pintura rupestre de la región atacameña que nos sirven de casos de estudio: los estilos Confluencia (Formativo Temprano, 1500-500 a.C.) y Cueva Blanca (Formativo Medio, 500 a.C.-100 d.C.). Estilos que fueron producidos socialmente, al igual que todos los restos materiales contemporáneos de las épocas que nos ocupan, y que se vinculan unos a otros por semejanza, contigüidad o contraste (Gallardo 1996). Relaciones significantes sustantivas para la arqueosemiótica, perspectiva cuya actividad se funda en el descubrimiento de los vínculos solidarios que establecen entre sí las intervenciones humanas sobre el entorno, desde el artefacto al paisaje.

\section{El Objeto de Estudio}

Por necesidad metodológica, estableceremos inicialmente la cualidad de nuestro objeto de análisis y su dominio de pertinencia, para posteriormente fijar su contexto de actualización. Nuestro objeto de estudio, que en este trabajo está circunscrito a la pintura rupestre, se nos presenta como representación, como la materialización visual de una Bildung (construcción-configuración) que se realiza en un dominio geográfico y época particular.

La pintura rupestre se instala como signo -como dato semiológico- en un espacio representacional predeterminado, seleccionado, elegido por el pintor que, siguiendo a George Steiner (1980:19), llamaremos un "contexto dinámico de conjunto". Este espacio compositivo se instaura como una unidad, en donde el signo actúa en y por un conjunto. A este conjunto le suponemos e imponemos una organicidad, lo devenimos en sistema sígnico, debido a la coherencia formal dada por el estilo que lo define. Categoría de análisis que remite al concepto de estilo o "modo distintivo de hacer" y que -en el arte que nos ocupa- se expresa como un conjunto de regularidades plásticas que permitieron al artista crear dentro de un dominio limitado formalmente (p.ej., Hegmon 1992). La noción de estilo nos fija la mirada en unas representaciones particulares y nos permite, a la vez, discriminar el conjunto de otras obras y estilos que forman parte del universo del arte rupestre del área en estudio.

En consecuencia, nuestro objeto de análisis son unas formas de representación que se particularizan por un estilo reconocible en una situación específica espacio-temporal. El plano semiótico en el que se fija el estilo-representación (Bildung) es el del significante, o lo que apropiadamente Llamazares (1986:19) llama: "reducción al significante". En tanto el signo rupestre ha perdido sus intérpretes originales, su interpretante (Peirce 1988:144), la simultaneidad del significante y el significado del signo queda reducida a su aspecto puramente material.

A partir de estos supuestos, el análisis debe comenzar por la determinación de los significantes rupestres que permiten fijar la mirada en unos procedimientos y formas específicas que, en su conjunto, suponen una organicidad, una geschtaltung, una configuración. Relaciones que se amplían contextualmente en tanto que las representaciones visuales operan por analogía con el mundo de los productores, con los objetos y seres que les rodeaban (p.ej., Marin 1978:173).

\section{Los Estilos Rupestres y sus Contextos Históricos Sociales}

La precordillera del desierto de Atacama, al igual que muchas localidades del norte de Chile, presenta un importante número de sitios de arte rupestre pertenecientes a distintas épocas. Se trata de universo variable desde el punto de vista de la forma, en él se han podido reconocer varias estrategias de construcción visual, tanto para grabados como para pintura (Berenguer 2004; Gallardo et al. 1999; Mege 2000; Núñez et al. 2006a; Pimentel y Montt 2008; Sepúlveda 2002; Vilches 1999). En este ensayo hemos seleccionado dos conjuntos de pinturas, que nuestros análisis sugieren organizados de acuerdo a diferentes convenciones gráficas, tanto para los diseños como para las composiciones, los estilos formativos Confluencia y Cueva Blanca (Figura 1 


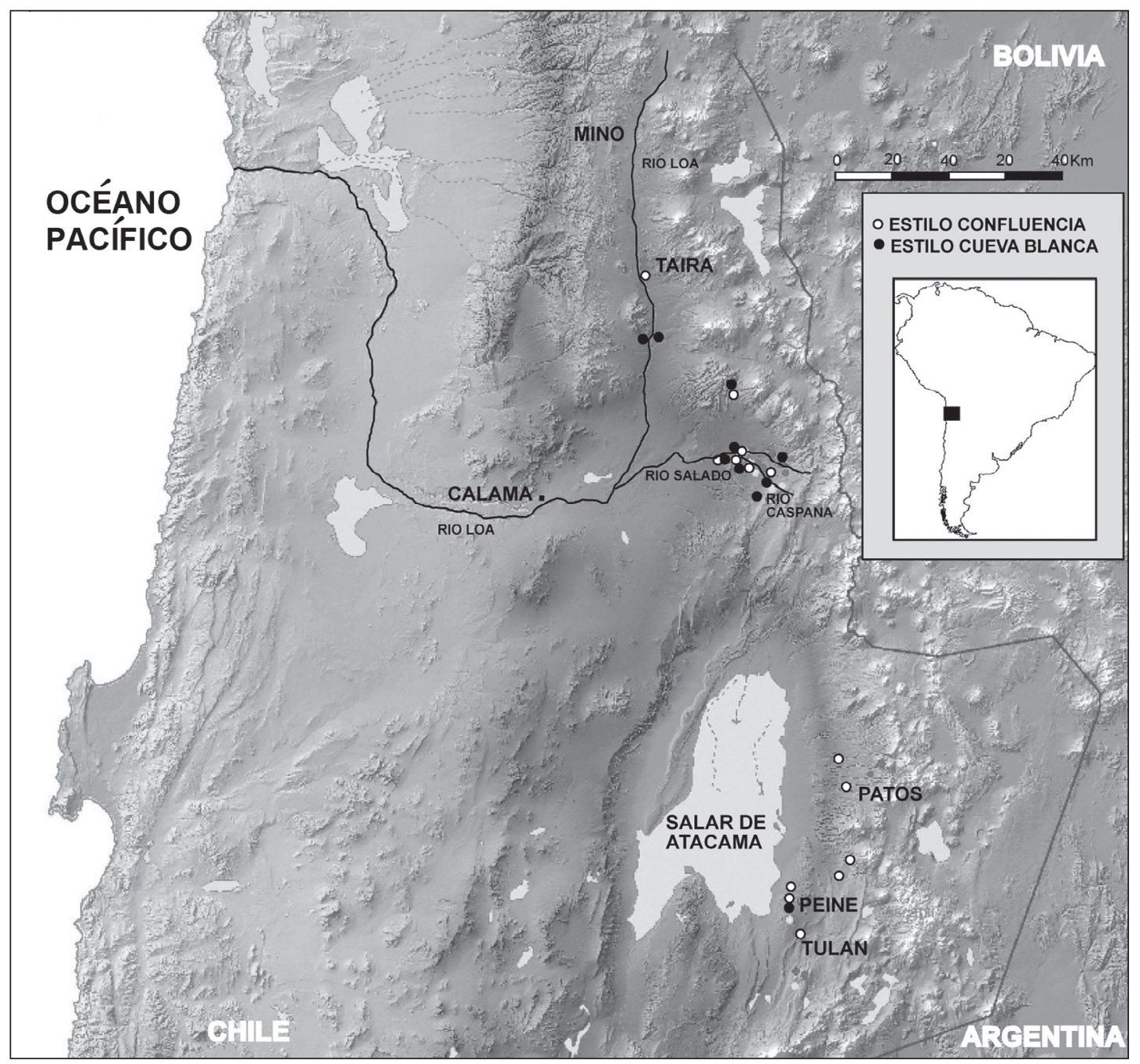

Figura 1. Distribución de los estilos Confluencia y Cueva Blanca en la región atacameña. Distribution of Confluencia and Cueva Blanca styles in the Atacama region.

y Tabla 1) (Berenguer 2004; Gallardo et al. 1999; Gallardo 2001; Núñez et al. 1997).

El estilo Confluencia reúne pinturas que dada su relación con lo representado puede ser considerado como naturalista, y tiene por distribución la cuenca del río Salado y precordillera del salar de Atacama, y en menor número el curso superior del río Loa (Figura 2). Las indicaciones históricas y culturales para este estilo provienen desde dos fuentes: los artefactos y actividades representadas y la asociación recurrente a depósitos de una misma época. Faldellines, dardos y propulsores y las actividades de caza correlativas sugieren una época tan temprana como el período Arcaico, sin embargo, los depósitos más antiguos en
Tabla 1. Pinturas rupestres, estilos formativos del desierto de Atacama.

Rock art painting, formative styles, Atacama desert.

\begin{tabular}{lll}
\hline \multicolumn{1}{c}{ Características } & \multicolumn{1}{c}{$\begin{array}{c}\text { Estilo } \\
\text { Confluencia }\end{array}$} & \multicolumn{1}{c}{$\begin{array}{c}\text { Estilo } \\
\text { Cueva Blanca }\end{array}$} \\
\hline Forma* & Naturalista & Geométrico \\
Color* & Monocromo & Policromo \\
Tamaño & Regular & Regular \\
Composición & Escénico & Simétrico \\
Superposición & No & No \\
Emplazamiento* & Abrigo rocoso & Abrigo rocoso \\
Distribución & Regional & Regional \\
\hline
\end{tabular}

*Generalmente, aunque no exclusivo. 
dos sitios con importantes paneles de este estilo en el río Salado han proporcionado fechas de radiocarbono que los sitúa durante el Formativo Temprano (1.500500 a.C.), época en la que se consolidan estrategias ganaderas, aunque en un ambiente económico donde la caza de fauna mayor no ha cedido a las nuevas presiones productivas (De Souza 2000; Gallardo 2001; Gallardo y De Souza 2008). Recientemente, una figura grabada y pinturas de camélidos con estos atributos han sido descubiertas en el muro interior del templete de Tulán, confirmado la cronología temprana propuesta hasta ahora, de 2.860 a 2.710 a.p. (Núñez et al. 2006b, Núñez et al. 2009). Este hallazgo es excepcional, pues son los únicos paneles de arte rupestre emplazados al interior de un conjunto residencial, conjunto residencial cuya importancia durante el formativo temprano cumplía con una función congregacional cuya importancia social era de carácter regional (Núñez et al. 2006b).

El estilo Cueva Blanca, a diferencia del anterior, es principalmente geométrico y se distribuye desde
Alto Loa hasta el extremo sur del salar de Atacama (Gallardo et al. 1999). Temporalmente se asocia al Formativo Medio (500 a.C.-100 d.C.), pues sus expresiones son correlativas al ámbito de los tejidos y su iconografía "Alto Ramírez" que aparecen en esta época en el río Loa (Sinclaire 1997) (Figura 3). Apreciación cronológica relativa que hemos confirmado mediante el fechado radiométrico de uno de los tapices emblemáticos del sitio Topater en las cercanías de Calama (Beta-259693, cal. 410-360 a.C., 2 sigmas, IntCal04) (Figura 4). Esta es una época de consolidación de la vida aldeana favorecida por la producción artesanal, la ganadería, la recolección del algarrobo, la agricultura inicial y el intercambio a larga distancia (Gallardo 2009a; Labarca y Gallardo 2012; Torres-Rouff et al. 2012). Característico de este momento histórico es la proliferación de aldeas con un patio o plaza que permitió ceremonias de carácter colectivo, una actividad de integración social que dará forma a las comunidades tempranas desde la quebrada
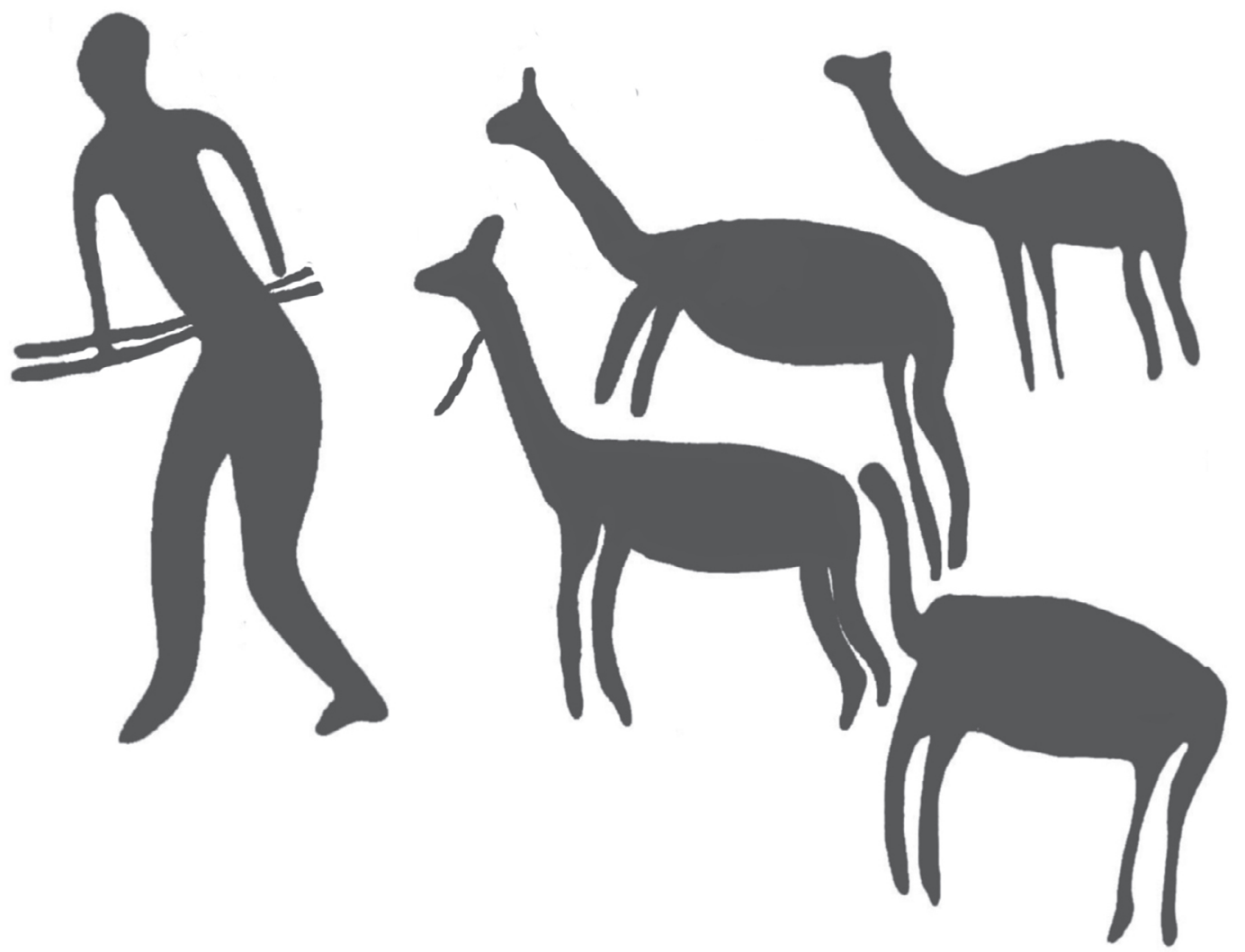

Figura 2. Cazador y camélidos silvestres cautivos (ancho 13,5 cm). Estilo Confluencia, Quebrada Patos. Hunter and wild camelids in captivity. Confluencia style, Patos ravine, Talabre (width $13.5 \mathrm{~cm}$ ). 


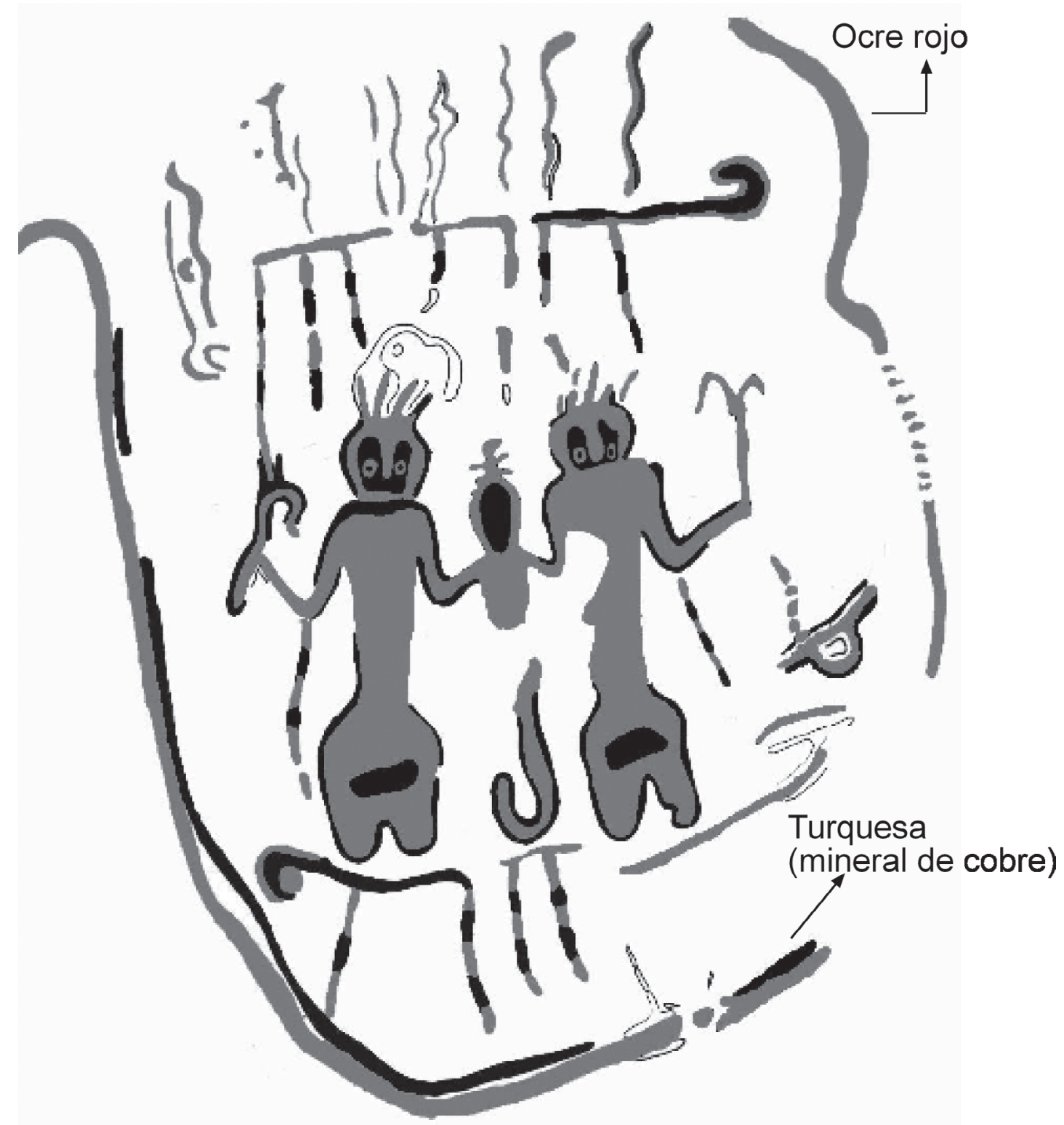

Figua 3. Pintura estilo Cueva Blanca (largo $31 \mathrm{~cm}$ ). Ocre rojo con aplicaciones turquesa. Incahuasi, localidad de Caspana. Cueva Blanca style painting (length $31 \mathrm{~cm}$ ). Red ocher with turquoise appliances. Incahuasi, Caspana locality.

de Tarapacá hasta el salar de Atacama (Adán et al. 2013).

\section{La Tarea Semiológica}

En este artículo consideramos el estilo como un conjunto de relaciones formales distintivas cuyo funcionamiento puede ser considerado un sistema semiótico. Sin embargo, esta decisión no puede ser tomada a priori, pues tales sistemas deben satisfacer condiciones que acrediten la presencia de un proceso de semiosis, de un universo de signos cuyo carácter es semiótico. Emile Benveniste (1978) ha propuesto los criterios elementales y necesarios para el establecimiento de un universo de este tipo, modelo que utilizaremos solo por un dictamen operacional para definir la pertinencia semiológica del arte rupestre considerado en este estudio. 


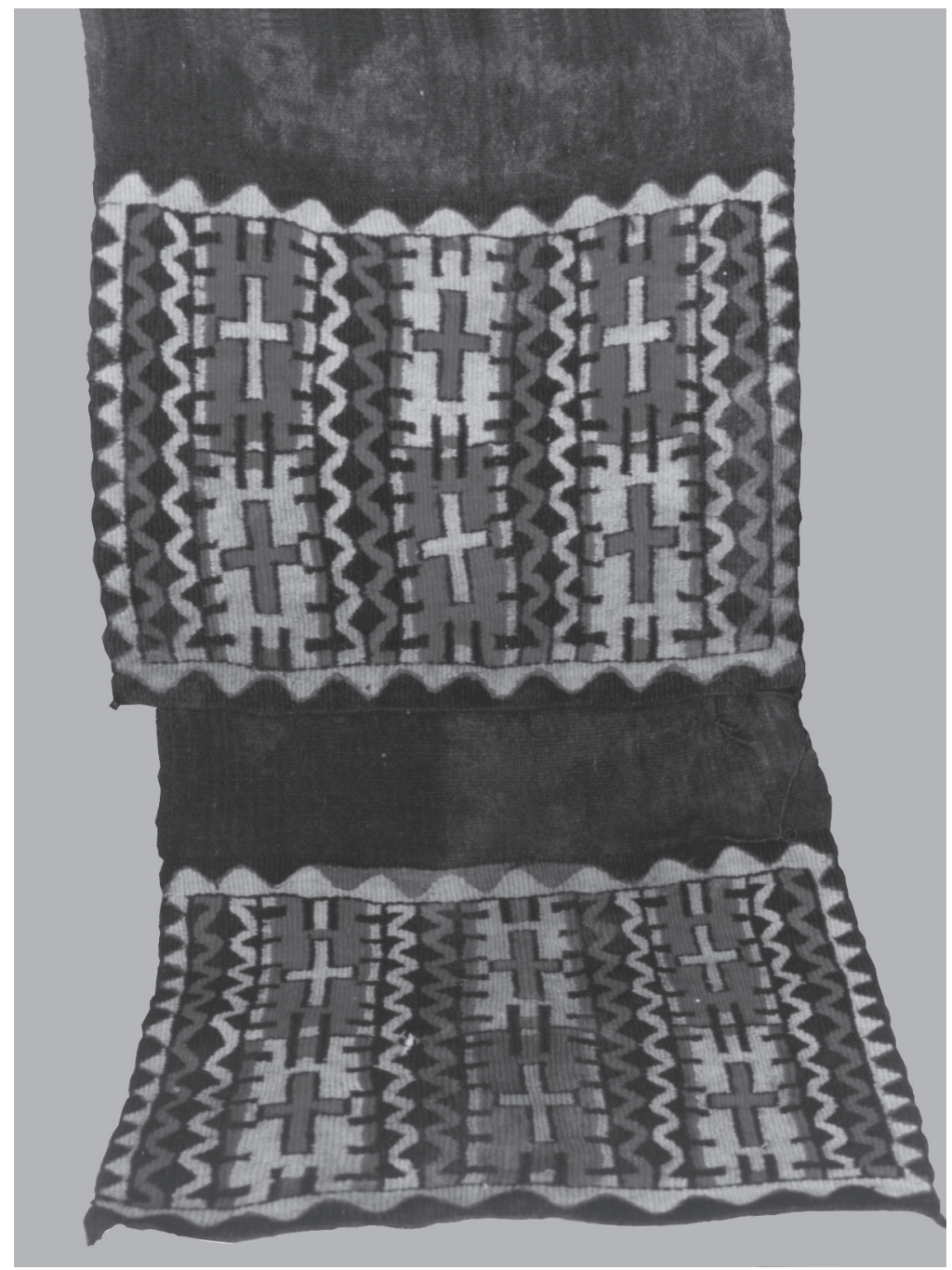

Figura 4. Textil del cementerio Topater (Calama) datado por radiocarbono. Radiocarbon-dated textile from Topater Cemetery (Calama).

Dentro de la semiología se distinguen dos dominios analíticos y metodológicos, el modo semiótico y el semántico. El primero de estos es el componente inicial de toda semiología, y el que mejor se ajusta a nuestros requerimientos heurísticos, dada la naturaleza de nuestro universo sígnico basado en relaciones entre significantes. El segundo modo guarda relación con los significados asentados en el discurso y, por consiguiente, algo inviable para la pintura rupestre considerada en este ensayo.

El modo semiótico funda lo semiótico, y "lo semiótico designa el modo de significancia que es propio del signo (...), lo constituye como unidad"
(Benveniste 1978:67). Su método "consistirá en identificar las unidades, en describir las marcas distintivas y en descubrir criterios cada vez más sutiles de distintividad" (Benveniste 1978:67).

\section{Caracterización de un Sistema Semiológico}

Benveniste (1978: 47-69) distingue cuatro características básicas para todo sistema semiológico: modo de operación, dominio de validez, naturaleza y número de sus signos y su tipo de funcionamiento. Distinciones arqueosemióticas que le exigiremos a los estilos rupestres como sistema semiológico. 


\section{Modo de operación}

El modo de operación de una imagen pictórica es visual, una relación que se establece entre un emisor y un receptor mediante una imagen, que es básicamente forma y color, una operación sobre la luz que excita y provoca el ojo del observador. La imagen es un artefacto visual, algo creado por alguien para una audiencia o para sí mismo, cuya función más elemental es hacer algo visible de un modo particular.

Se reconocen aquí distintos dispositivos visuales generales al dominio pictórico (p.ej., Gallardo 1992, 2005). Mientras el estilo Confluencia tiende a favorecer el uso de áreas continuas, el estilo Cueva Blanca incorpora con mayor énfasis tratamientos lineales continuos y discontinuos. Operaciones que aportan mayor número de intervenciones e información visual, creando un contexto de "lectura" para una competencia particular. Sofisticaciones visuales que no son ajenas al estilo Confluencia, pues los artistas desarrollaron un efecto de transparencia que daba solución al modo de expresión bidimensional dominante, logro que era logrado superponiendo en una misma figura dos planos, uno que indica las extremidades inferiores y otro que hace alusión a un faldellín de múltiples pabilos (Montt 2002).

El tamaño de estas obras no difieren grandemente entre sí, pero debe destacarse que las diferencias de color entre ambas podrían operar cognitiva y semióticamente como una fuente de jerarquización del espacio rupestre, distinción que sería acentuada por la policromía del estilo Cueva Blanca. Decisiones pictóricas que introducirían diferencias en las cantidades relativas de pigmentos utilizados en la producción de las obras, consumo material que permitiría una definición arqueológica del valor diferencial de estas obras. Se podría decir que el tamaño es entonces solo una expresión del gasto material requerido en la visualización, de la riqueza social invertida en la configuración de ese capital simbólico en particular.

\section{Dominio de validez}

El dominio de validez es aquel donde el sistema semiótico se impone y deber ser reconocido u obedecido. En el arte rupestre, este dominio puede ser encontrado en su emplazamiento. Lugares que al ser intervenidos visualmente son modificados en su estructura espacial, proporcionando discontinuidades favorables para un discurso de carácter simbólico o ritual, para la "construcción" de un entorno culturalmente significativo (p.ej., Troncoso 2005).

En el caso de los estilos que nos ocupan, con excepción de Tulan, ambos suelen estar al interior de abrigos rocosos junto a quebradas con aguas de escurrimiento permanente, muchos de los cuales sirvieron de habitación temporal para los antiguos habitantes de la localidad. Este emplazamiento preferencial es propio de estos estilos, pues es claramente diferente a aquellos otros definidos para la localidad (p.ej., el estilo Quebrada Seca), donde el arte rupestre es instalado cercano a los campos de cultivo y en las inmediaciones o al interior de las aldeas más tardías (p.ej., Gallardo 2001; Gallardo y Vilches 2001; Sepúlveda 2002). Nuestros sondajes sugieren el uso de estos espacios restringidos en función de actividades de caza y circulación dentro del área de quebradas altoandinas (Sinclaire 2004). Lo que refuerza la idea que los contenidos de este arte estaban dirigidos mayormente hacia el interior del grupo social, más que hacia aquellos que provenían del exterior.

\section{La naturaleza [constitución] y el número de sus signos}

Hablaremos de un signo como una unidad distintiva y opositiva, como unidades discriminadas por estilos de representación. Unidades-signos que obedecen a un estilo-período que define sus sistemáticas. Benveniste nos advierte que "no hay signo transistemático" (Benveniste 1978:57), cada estilo-período es excluyente con sus signosunidades. También hay que considerar que, "todo sistema semiológico que descanse en signos tiene por fuerza que incluir: un repertorio finito de signos" (Benveniste 1978:60). En nuestro caso, significantes.

\section{La pintura rupestre y sus unidades}

El estilo Confluencia corresponde principalmente a figuras confeccionadas con pigmentos rojos (aunque también está presente el amarillo y el blanco) y sus referentes principales son los camélidos y su número es dos veces mayor que el de los humanos. Sus formas retienen aspectos de la anatomía corporal, los efectos de animación son generalizados y casi la totalidad de ellos son mostrados de semiperfil. Por lo general, 
llevan prendas de atuendo y armas (Gallardo 2001; Gallardo y Vilches 1996) (Figura 5A).

Como hemos dicho, el estilo Cueva Blanca es radicalmente distinto a Confluencia. En este predominan las figuras humanas y disminuyen casi totalmente las de camélidos Los humanos son principalmente construidos de manera frontal, carecen de animación y aumentan significativamente los diseños como líneas onduladas, en zigzag y cruces (Figura 5B).

\section{Plano del significado: indexial}

Los signos de la pintura rupestre pueden fácilmente transformarse en símbolos migrantes, como los llamó inicialmente Wittkower (1977), al transitar de manera homóloga por diferentes contextos culturales. En nuestro caso, desde el sistema semiológico de los pintores rupestres al sistema de análisis semiológico del arqueosemiólogo. Está claro que Wittkower pensó en algo distinto cuando acuñó el término de signos migrantes, pues es el investigador el que emigra al signo por contextos que no le son propios, sometiéndolo a nuevos significados al contar solo con sus significantes. Evidentemente, los significados denotativos siempre estarán ausentes, pero es evidente que la imagen misma es un aspecto sustantivo de este proceso, por lo cual no es incorrecto operar con aquellos contenidos indexiales que aluden a un referente animal, humano o artefactual. Designaciones que, en última instancia, nos permiten operar con las unidades distintivas de cada estilo.

Sin duda, la indexialidad descansa en las decisiones del artista, quien al trabajar sobre el mundo de lo visible -algo socialmente aprendidosabe traducir un concepto en un diagrama espacial (diagrama según Barthes 1986; esquema según Gombrich 1988). Este proceso de la producción de la imagen (que es una mezcla de conocimientos cognitivos y culturales) puede estar orientada al reconocimiento (una interpretación inducida socialmente) o la digresión (una interpretación individual). En el primer caso, el artista trabajará sobre un diagrama espacial diseñado para activar la competencia semiótica, apelando al conocimiento previo del espectador. En el segundo, como es obvio, evitará toda referencia a la memoria visual y cultural del espectador, invocando la actualización semiótica.

Aunque en relación con el espectador o interpretante, la semiosis es un proceso irrevocable, es evidente que una imagen apela a la competencia cultural y la otra a la idiosincrasia del sujeto. En nuestro caso de estudio, las obras visuales se sitúan por definición en el campo del conocimiento social, pues se trata de estilos, conjuntos distintivos producto de convenciones históricas y culturales. Como hemos dicho, el aspecto denotativo nos está vedado, sin embargo, como analistas podemos distinguir unidades, diferencias y relaciones. $Y$ esto no solo por un dictamen metodológico, sino porque los artistas necesariamente debieron trabajar sobre estos mismos problemas para comunicar.

Teniendo en cuenta el argumento precedente, podemos indicar que para el Estilo Confluencia los significantes se reducen básicamente a figuras humanas y animales en actividad, a las que se les ha proporcionado un conjunto diverso de atributos anatómicos y efectos de animación. La distintividad de estos es compleja, pues los humanos suelen llevar en distintas combinaciones propulsores y dardos, faldellines y tocados, y los animales (particularmente camélidos) han sido dotados de gestos en patas, cuellos y colas relativos al comportamiento de agresión que es el medio a través del cual se organizan socialmente los rebaños (González 2002). Más aún, la información visual relativa a la anatomía de estos últimos sugiere la presencia de camélidos silvestres (Gallardo y Yacobaccio 2007).

El Estilo Cueva Blanca difiere sustantivamente del anterior, pues inaugura un nuevo modo de representación, con figuras humanas frontales desdobladas, en reposo y algunos elementos de indumentaria, en asociación con diversas figuras geométricas (o referentes fuera de nuestra competencia semiótica). A diferencia de Confluencia, la indexialdad de Cueva Blanca no reside en sus unidades, sino en el efecto de conjunto. Pues como hemos señalado sigue el patrón de diseño típico de los textiles "Alto Ramírez" de inicios del periodo Formativo Medio (Figura 6).

\section{El color}

Los colores son elementos constituyentes de las unidades semióticas rupestres. Los colores los definiremos como colores netos, sin considerar las tonalidades de estos, ya que su sutil variación no los hace susceptibles de discreción semiótica. Diversos procesos postdepositacionales han actuado sobre ellos, introduciendo un amplio espectro de tonalidades. Tampoco tenemos la palabra de 

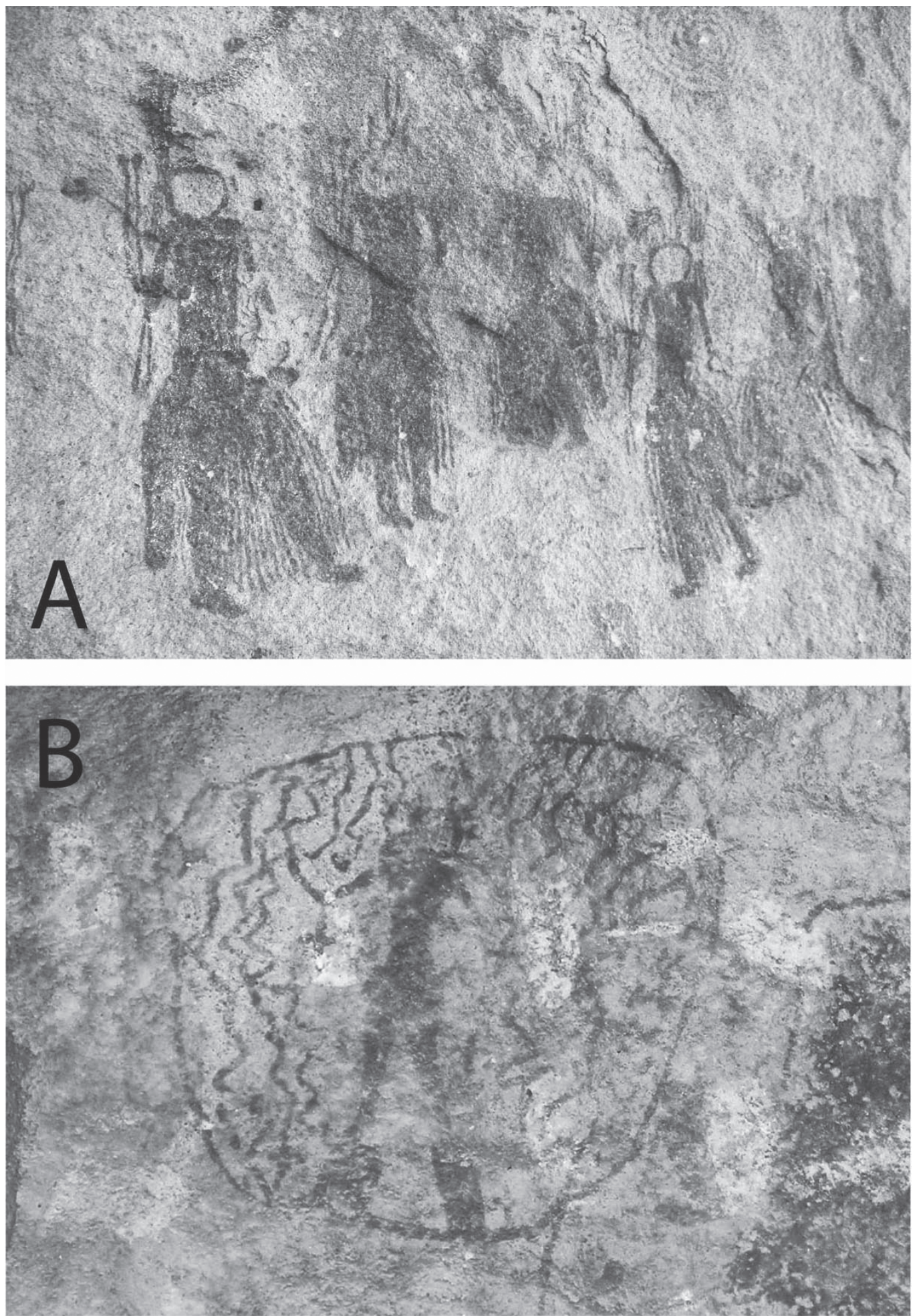

Figura 5. A. Cazadores Estilo Confluencia en ocre rojo, Quebrada Patos (largo 24 cm). B. Composición Estilo Cueva Blanca en ocre rojo, confluencia ríos Caspana y Salado (largo 20,5 cm).

Confluencia Style Hunters in red ochre, Patos ravine, Talabre (length $24 \mathrm{~cm})$. B. Cueva Blanca Style Composition in red ochre, Caspana and Salado rivers confluence (length $20.5 \mathrm{~cm}$ ). 

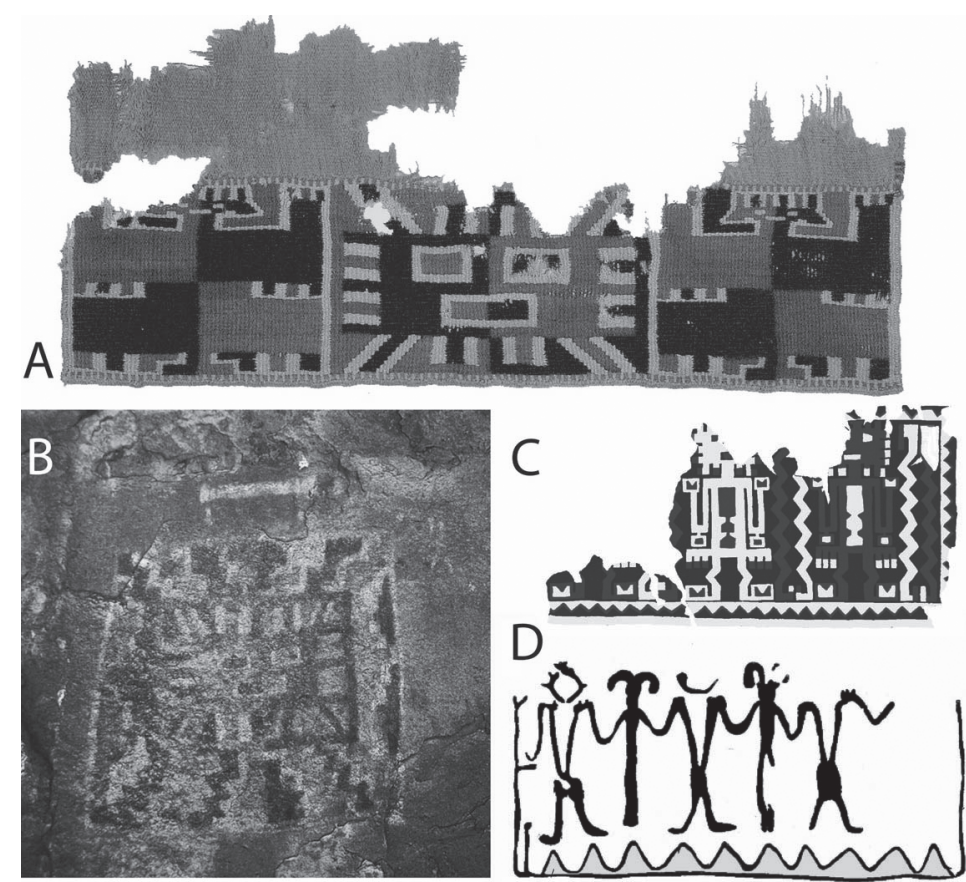

Figura 6. A. Textil Estilo Alto Ramírez, valle de Azapa, Arica. B. Icono Estilo Alto Ramírez, ocre rojo y blanco, río Loa (ancho $80 \mathrm{~cm}$ ). C. Textil Estilo Alto Ramírez, río Loa, Calama (ancho $41 \mathrm{~cm}$ ). D. Pintura estilo Cueva Blanca, ocre rojo y blanco, Alero de Aiquina, río Salado (ancho 40,5).

A. Alto Ramírez Style textile, Azapa river. B. Alto Ramírez Icon, white and red ochre, Loa river (width $80 \mathrm{~cm}$ ). C. Alto Ramírez style textile, Loa river, Calama (width 41 $\mathrm{cm})$. D. Painting Cueva Blanca style, white and red ochre, Aiquina shelter, Salado river (wide $40.5 \mathrm{~cm}$ ).

los pintores originarios, para que clasifiquen categorialmente cada color por su nombre. Solo nos queda abstraer de esa evidencia difusa ( $f u z z y$ ) el significante del color, y considerar toda la amplia variedad del espectro bajo una noción logística de término para cada significante de color (Langer 1969:32-33), integradora de las particularidades cromáticas, elementales, constituyéndose por ejemplo, el término rojo para los elementos de los rojos.

Desde un punto de vista del color, podemos establecer tres soluciones paradigmáticas. La primera de estas soluciones de color la llamaremos "constitutiva", pues opera a partir de un principio constructivo, en donde las figuras coinciden con el de color, es decir, la forma coincide con el color, la configuración formal es indiferenciada respecto de la configuración del color. El color hace la forma y la forma está construida por el color, abarcada por color, estableciéndose una relación mecánica entre un color y una forma, entre unos colores y unas formas. Este esquema es transversal a ambos estilos.

La segunda solución paradigmática de color es propia del estilo Confluencia, y no es más que la complicación de la primera, pues usa la estrategia de configuración forma-color como un soporte de color (siempre rojo), para otros colores (como el amarillo y el blanco), que se aplican como marcas semióticas sobre el color de fondo; a esta solución la denominaremos "aplicativa". Sobre el soporte monocromo se aplican otros significantes, como líneas, puntos o áreas limitadas de pintura. Este procedimiento complejiza las figuras y amplía su diversidad y singularidad. Su uso es principalmente funcional al referente, pues designa las cuentas de un collar, el tocado de plumas, el pelaje más claro del vientre de las vicuñas o la pintura corporal (Figura 7).

La tercera solución de color es característica del estilo Cueva Blanca. Se basa en una construcción compleja de la forma, a partir de combinaciones 


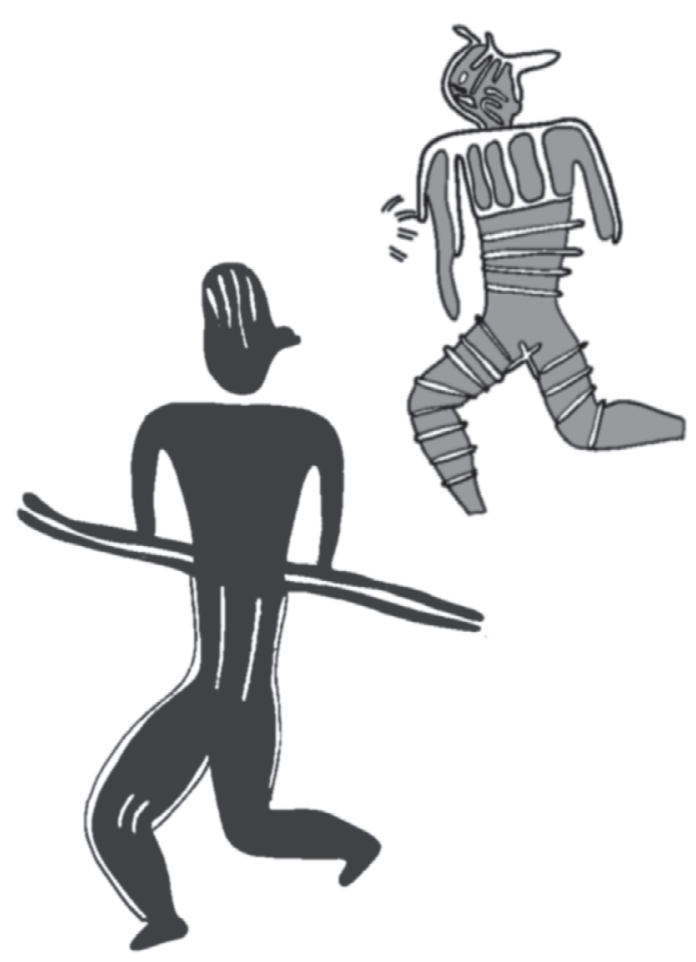

Figura 7. Cazadores estilo Confluencia (largo $26 \mathrm{~cm}$ ). Figura superior, ocre amarillo con aplicaciones blancas. Figura inferior, ocre rojo con aplicaciones blancas. Alero El Pescador, río Caspana. Confluencia style Hunters (length $26 \mathrm{~cm}$ ). Top figure, yellow ocher with white appliances. Figure below, red ocher with white appliances. El Pescador shelter, Caspana river.

y alternancias de colores. En el primer caso, los colores componen la figura a partir de diferentes patrones de color, como son borde/centro o perímetro/ centro. Y en el segundo caso, los colores se alternan en series de combinaciones. A esta le llamaremos "alternante" (Figura 3).

En los modos aplicativos y alternantes, el color se instala como problemático, ya que su complejidad en relación con la forma los hace visibles. Es decir, el color interviene agregando un elemento inquietante, de inestabilidad: ¿significan los colores dentro, en el perfil de la forma? En el esquema constitutivo, forma y color se confunden, en los otros dos el color desestabiliza la representación. El color dibuja la forma, la invade, haciéndose visible. La monocromía estabiliza a la forma, la policromía, la fragmenta al dividir la totalidad de la forma, al discriminar significantes hacia el interior de esta. El color tiene una función segmentadora del significante, agregándole densidad a la forma.

\section{Tipo de funcionamiento}

De acuerdo a Benveniste:

Las artes figurativas, participan de otro nivel [que el signo lingüístico], el de la representación, donde rasgo, color, movimiento, se combinan y entran en conjuntos gobernados por necesidades propias, (...) las relaciones significantes del "lenguaje" artístico hay que descubrirlas dentro de una composición" (Benveniste 1978:62).

Por consiguiente, el tipo de funcionamiento es la relación que une a los significantes, es su modo de estructuración espacial distintivo.

Hasta ahora, hemos seleccionado para la constitución de nuestras unidades semióticas dos componentes: rasgos, variaciones representacionales significativas, dentro de conjuntos de unidades y color, elemento constituyente de las unidades semióticas. Estos elementos concurren en una composición que llamaremos esquema, que no es más que una estructura distribucional de unidades semióticas discretas y solidarias (Harris 1951).

El funcionamiento del sistema es de orden paradigmático: relaciones estructurales asociativas entre las unidades representacionales, que aquí hemos llamado unidades-signos.

Todo sistema semiológico que descanse en signos tiene por fuerza que incluir: reglas de disposición que gobiernan sus figuras, independientemente de la naturaleza y del número de los discursos que el sistema permita producir (Benveniste 1978:60).

Las reglas que gobiernan el funcionamiento del sistema las llamamos paradigmas representacionales, que operan a partir de una lógica asociativa, que somete a las unidades-signos a patrones representacionales, a determinados esquemas o movimientos de composición.

\section{Esquemas o Movimientos}

Siguiendo esta metodología semiótica de análisis de la pintura rupestre, discreta y heterodoxa, estableceremos para nuestro universo de representaciones dos paradigmas claramente diferenciados (Gallardo 2009b). 
El esquema paradigmático de balance por acción, propio del estilo Confluencia, sigue una estrategia de composición a partir de la compensación de las figuras en su soporte. Estas establecen su equilibrio compositivo a partir de sus vinculaciones de actividad. Existe en ellas una solidaridad de conjunto, cuya tensión recíproca da como resultado una escena. La indicación de conjunto es la actividad de animales, humanos y relaciones entre estos.

El esquema paradigmático de balance por axialidad, característico del estilo Cueva Blanca, sigue un patrón de desdoblamiento especular de las figuras. Hay evidentemente, no solo una distinta realización del movimiento, en la articulación de como se asocian los significantes y sus rasgos, sino que supone una configuración total de la composición en simetría. Desde el punto de vista de la composición se privilegia la ortogonalidad, la simetría especular y la traslación, y estos procedimientos afectan también al color (Gallardo et al. 1999; González 2005; Sinclaire 1997).

\section{Epílogo}

La configuración paradigmática general, que se ha revelado como un aspecto sustantivo de los estilos de pintura rupestre analizados, se nos presentan a partir de dos esquemas iniciales de representación paradigmática: los de acción y axialidad. Cada esquema lo hemos construido a partir de un factor compositivo, es decir, la espacialidad que edifica la obra a partir de las figuras dentro de cada estilo. El factor compositivo supone: (1) una estructura distributiva (relaciones entre las unidades significantes) lo que produce una peculiar configuración entre las unidades, compensada en uno y reflejado en otro; (2) unas unidades significantes, que según sus particulares características figurativasmprovocan un efecto determinado, dinámico o estático; y por último, (3) unas referencialidades que nos permiten vincular las representaciones significantes del arte con los conocimientos del artista sobre su entorno y cultura material, en otras palabras, una actividad del analista que significa, nombra o expresa motivado por la asociación intercontextual. En el esquema de balance, las figuras están en relación recíproca debido a que las imágenes son dispuestas aludiendo a una actividad, su expresión es escénica. En el esquema de axialidad, las figuras están en una relación de distribución espacial que alude a las imágenes textiles, su expresión es desdoblada.

Toda gramática, o sintáctica, en definitiva, toda sintagmática, parece improbable en el dominio de la pintura rupestre, más bien se trataría de "mensajes convencionales, producidos en una topología convencional donde las figuras ocupan puestos simbólicos, conformes a representaciones familiares" (Benveniste 1978:63). Los elementos que conforman la pintura rupestre no lograrían conformar unidades discretas y significantes, sería "solo en la composición donde se organizan y adquieren, técnicamente hablando, una significación, por la selección y la disposición" (Benveniste 1978:62).

Estos sistemas son consustanciales a los de modos de ver y al mismo tiempo son la expresión de un modo de pensar. Sin duda, los estilos analizados objetivan expectativas del imaginario, y ahora es claro que en un nivel profundo Confluencia privilegia las relaciones y la asociatividad de los humanos y animales, mientras Cueva Blanca precisa sus relaciones básicamente como relaciones que afectan tanto a la forma como al color. Mientras Confluencia eleva a patrimonio del imaginario las actividades de los cazadores (captura y cautividad de animales silvestres) en un ambiente donde el pastoralismo era políticamente dominante (Gallardo y De Souza 2008), Cueva Blanca alude al mundo de los objetos y las estructuras textiles, a los tejidos como bienes de prestigio, objetos que debieron estar al servicio de los liderazgos intercomunitarios emergentes de la época (Gallardo 2009a). Ciertamente este enfoque estructural o arqueosemiótico favorece la identificación de cambios históricos sustantivos en los imaginarios rupestres y sociales (p.ej., Preucel 2010:8-14), sin embargo, estas soluciones semióticas necesariamente deberán ser examinadas en el contexto de las prácticas que le confieren un valor relativo.

Agradecimientos: Comprometen nuestra gratitud los distintos colegas que han formado parte de nuestras investigaciones por más de 10 años, estudios que fueron posible debido al financiamiento de los Proyectos FONDECYT \# 1950101, \#1980200 y \#1070083. También el proyecto FONDAP 15110006 que nos permitió elaborar el actual manuscrito y el Museo Chileno de Arte Precolombino que ofició como institución patrocinante. A los evaluadores por su paciencia y enorme comprensión. 


\section{Referencias Citadas}

Adán, L., S. Urbina, C. Pellegrino y C. Agüero 2013. Aldeas en los bosques de prosopis. Arquitectura residencial y congregacional en el Período Formativo tarapaqueño (900 ac-900 dc). Estudios Atacameños 45:75-94.

Barthes, R. 1986. Mitologías. Siglo Veintiuno Editores, México, D.F.

Benveniste, E. 1978. Problemas de Lingüística General II. Siglo Veintiuno Editores, México, D.F.

Berenguer, J. 2004. Cinco milenios de arte rupestre en los Andes atacameños: Imágenes para lo humano, imágenes para lo divino. Boletín del Museo Chileno de Arte Precolombino 9:75-108.

Berger, J. 1975. Modos de Ver. Editorial Gustavo Gili S.A., Barcelona.

De Souza, P. 2004. Tecnologías de proyectil durante los períodos arcaico y formativo en el Loa superior: una aproximación inicial a partir de las puntas líticas. Actas del XV Congreso Nacional de Arqueología Chilena. Chungara Revista de Antropología Chilena Volumen Especial Tomo I, pp. 61-76.

Gallardo, F. 1992. Conceptos básicos de arte rupestre. Boletín de la Sociedad Chilena de Arqueología 15:19-21.

Gallardo, F. 1996. Acerca de la lógica en la interpretación del arte rupestre. Boletín de la Sociedad Chilena de Arqueología 23:31-33.

Gallardo, F. 2001. Arte rupestre y emplazamiento durante el Formativo Temprano en la cuenca del río Salado (Desierto de Atacama, norte de Chile). Boletín del Museo Chileno de Arte Precolombino 8:81-95.

Gallardo, F. 2005. Notas sobre la construcción de la imagen en el arte rupestre. Boletín de la Sociedad Chilena de Arqueología $38: 45-51$

Gallardo, F. 2009a. Social interaction and early rock art styles in the Atacama Desert (Northern Chile). Antiquity 83:619-633.

Gallardo, F. 2009b. Sobre la composición y la disposición en el arte rupestre de Chile: Consideraciones metodológicas. Magallania 37:19-38.

Gallardo, F. y P. De Souza 2008. Rock art, modes of production and social identities during the Early Formative Period in the Atacama Desert (Northern Chile). En Archaelogies of Art: Time, Place, and Identity, editado por D. Fiore, I. Domingo y S. May, pp. 79-97. Left Coast Press, Walnut Creek.

Gallardo, F., C. Sinclaire y C. Silva 1999. Arte rupestre, emplazamiento y paisaje en la cordillera del desierto de Atacama. En Arte Rupestre en los Andes de Capricornio, editado por J. Berenguer y F. Gallardo, pp. 57-96. Museo Chileno de Arte Precolombino, Santiago.

Gallardo, F. y F. Vilches 1996. An original rock art style in the Atacama Desert (Northern Chile). International Newsletter on Rock Art 15:14-17.

Gallardo, F. y F. Vilches 2001. Arte rupestre en la época de dominación inka en el norte de Chile. En Tras la Huella del Inka en Chile, editado por C. Aldunate y L. Cornejo, pp. 34-37. Museo Chileno de Arte Precolombino, Santiago.
Gallardo, F. y H. Yacobaccio 2007. ¿Silvestres o domesticados? Camélidos en el arte rupestre del formativo temprano en el desierto de Atacama. Boletín del Museo Chileno de Arte Precolombino 12:9-31.

Gombrich, E. 2002. Arte e Ilusión. Phaidon Press, New York.

González, J. 2002. Etología de Camélidos y arte rupestre de la subregión del río Salado (Norte de Chile, II Región). Estudios Atacameños 23:23-32.

González, P. 2005. Códigos visuales de las pinturas rupestres Cueva Blanca: formas, simetría y contexto. Boletín del Museo Chileno de Arte Precolombino 10:55-72.

Harris, Z. 1951. Method in Structural Linguistics. University of Chicago Press, Chicago.

Hegmon, M. 1992. Archaeological research on style. Annual Review of Anthropology 21:517-536.

Kechagia, H. 1995. The row and the circle: Semiotic perspective of visual thinking. Rock Art Research 12:109-116.

Labarca, R. y F. Gallardo 2012. The Domestic Camelids (Cetartiodactyla: Camelidae) from the Middle Formative Cemetery of Topater 1 (Atacama Desert, Northern Chile): Osteometric and Palaeopathological Evidence of Cargo Animals. (18 agosto). http://onlinelibrary.wiley.com/doi/10.1002/oa.2263/abstract (19 mayo 2014).

Langer, S. 1969. Introducción a la Lógica Simbólica. Siglo Veintiuno Editores, México, D.F.

Llamazares, A. 1986. Hacia una definición de Semiosis. Reflexiones sobre su aplicabilidad para la interpretación del arte rupestre. Cuadernos Instituto Nacional de Antropología 11:1-47.

Marín, L. 1978. Estudios Semiológicos. La Lectura de la Imagen. Editorial Comunicación, Madrid.

Mege, P. 2000. Originales contra la fuerza. Boletín de la Sociedad Chilena de Arqueología 30:41-46.

Montt, I. 2002. Faldellines del período Formativo en el Norte Grande: un ensayo acerca de la historia de su construcción visual. Estudios Atacameños 23:7-22.

Núñez, L., I. Cartajena, C. Carrasco, P. De Souza y M. Grosjean 2006a. Patrones, cronología y distribución del arte rupestre arcaico tardío y formativo temprano en la cuenca de Atacama. En Tramas en la Piedra, editado por D. Fiore y M. Podestá, pp. 191-204. Sociedad Argentina de Antropología, Buenos Aires.

Núñez, L., I. Cartajena, C. Carrasco, P. De Souza y M. Grosjean 2006b. Emergencia de comunidades pastoralistas formativas en el sureste de la puna de Atacama. Estudios Atacameños 32:93-117.

Núñez, L., I. Cartajena, J. Loo, S. Ramos, T. Cruz, T Cruz y H. Ramírez 1997. Registro e investigación del arte rupestre en la Cuenca de Atacama (Informe Preliminar). Estudios Atacameños 14:307-325.

Núñez, L., I. Cartajena, P. De Souza y C. Carrasco 2009. Los estilos Confluencia y Taura Tulán: Ritos rupestres del formativo temprano en el sureste del Salar de Atacama. En Crónicas sobre la Piedra, editado por M. Sepúlveda, L. Briones y J. Chacama, pp. 205-220, Universidad de Tarapacá, Arica. 
Peirce, Ch. 1988. El Hombre, un Signo. Editorial Crítica, Barcelona.

Pike, K. 1943. Phonetics: A Critical Analysis of Phonetic Theory and a Technique for the Practical Description of Sounds. University of Michigan Press, Ann Arbor.

Pimentel, G. e I. Montt 2008. Tarapacá en Atacama. Arte rupestre y relaciones intersocietales entre el 900 y 1450 d.C. Boletín del Museo Chileno de Arte Precolombino 13:35-50.

Preucel, R.W. 2010. Archaeological Semiotics. Blackwell, Oxford.

Sepúlveda, M. 2002. Imagen Rupestre y Espacialidad en el Desierto de Atacama durante los Períodos Tardios (950-1550 d.C.). Memoria para optar al Título de Arqueóloga, Departamento de Antropología, Universidad de Chile, Santiago.

Sinclaire, C. 1997. Pinturas rupestres y textiles formativos en la región atacameña: paralelos iconográficos. Estudios Atacameños 14:327-338.

Sinclaire, C. 2004. Prehistoria del periodo Formativo en la cuenca alta del río Salado (Región del Loa superior). Chungara Revista de Antropología Chilena Volumen Especial Tomo II, pp. 619-639.
Sonesson, G. 1994. Prolegomena to the semiotic analysis of prehistoric visual display. Semiotica 100:267-332.

Steiner, G. 1980. Después de Babel. Aspectos del Lenguaje y la Traducción. Fondo de Cultura Económica, México, D.F.

Torres-Rouff, C., W.J. Pestle y F. Gallardo 2012. Eating fish in the driest desert in the world: osteological and biogeochemical analyses of human skeletal remains from the San Salvador cemetery, north Chile. Latin American Antiquity 23:51-69.

Troncoso, A. 2005. Hacia una semiótica del arte rupestre de la cuenca superior del río Aconcagua, Chile central. Chungara Revista de Antropología Chilena 37:21-35.

Vilches, F. 1999. Inka Rock Art? Minor Arts, Major Meanings. Thesis submitted to the Faculty of the University of Maryland at College Park in partial fullfillment of the requirements for the degree of Master of Arts, Maryland.

Wittkower, R. 1977. Allegory and the Migration of Symbols. Thames \& Hudson, London.

\section{Nota}

Robert W. Preucel (2010) ha hecho un recorrido por el amplio universo de la semiología inicial, sus semióticas actuales y hasta ciertos aportes cognitivistas, que suponen un recorte heterodoxo similar al que hacemos aquí. No hay pretensión de fijar una metodología, sino de ilustrar las posibilidades del método. Su elección sigue una línea histórica de la resolución del método, generando puentes con la disciplina arqueológica, muy libremente, diríamos, a su antojo; que es el mismo camino que hemos tomado para nuestra arqueosemiótica. 